See Article page 141.

\section{Commentary: Hybrid advice in the real world}

Diana Hsu, MD, and Alden Harken, MD

The final Cox-maze IV "cut-and-sew" iteration of Jim Cox's pioneering surgical procedure for the treatment of atrial fibrillation obligates a sternotomy, cardiopulmonary bypass, and, in Jim Cox's words, "can be technically challenging in a deep chested male with a small left atrium." It has proven, however, to be gratifyingly-even astonishingly - successful. The procedure is undeniably, however, "a lot of surgery," which tends to frighten cardiologists and their patients. So, a storm of innovators have proposed a barrage of hybrid procedures with the primary goal of accomplishing all of the transmural bi-atrial conduction blocking lesions without resorting to the sternotomy and cardiopulmonary bypass.

Clinical investigation is really very hard to do. Therefore, the surgical and electrophysiological innovators have all taken the logical first steps. They have devised, and tried, dual/hybrid procedures typically marrying thoracoscopic (occasionally robotic) —-(small incision), epicardial access with transvenous/transarterial catheter ablation using radiofrequency and or cryo-/heat ablative conduction blocking techniques. They have also recruited a mélange of patients with chronic atrial fibrillation mixed with paroxysmal atrial fibrillation on (or not) taking an anti-dysrhythmic soup of medications with variable duration follow-up surveillance strategies.

Again, for those armchair purists-who have never attempted a comprehensive clinical study - these trials are really hard to do. So, the real beauty of the current analysis is that Varzaly and colleagues ${ }^{1}$ have placed themselves in

\footnotetext{
From the UCSF-East Bay, Oakland, Calif.

Disclosures: The authors reported no conflicts of interest.

The Journal policy requires editors and reviewers to disclose conflicts of interest and to decline handling or reviewing manuscripts for which they may have a conflict of interest. The editors and reviewers of this article have no conflicts of interest.

Received for publication July 12, 2021; revisions received July 12, 2021; accepted for publication July 12, 2021; available ahead of print July 27, 2021.

Address for reprints: Diana Hsu, MD, UCSF-East Bay, Highland Hospital, 1411

East 31st St, QIC 22134, Oakland, CA 94602 (E-mail: dianahsu20@gmail.com

ordianahsu@alamedahealthsystem.org).

JTCVS Open 2021;7:155

2666-2736

Copyright (C) 2021 The Author(s). Published by Elsevier Inc. on behalf of The American Association for Thoracic Surgery. This is an open access article under the CC BY-NC-ND license (http://creativecommons.org/licenses/by-nc-nd/4.0/). https://doi.org/10.1016/j.xjon.2021.07.006
}

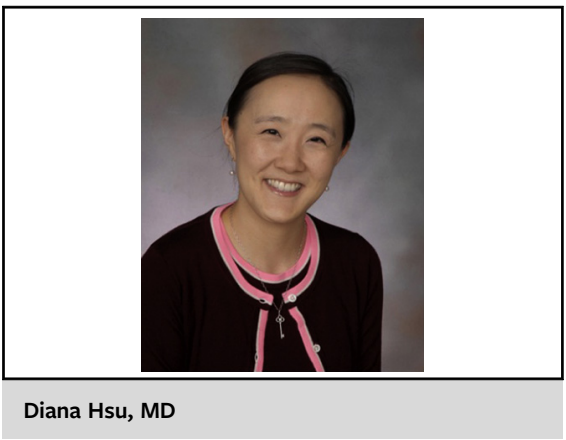

\section{CENTRAL MESSAGE \\ If we restricted our authoritative advice to our unsuspecting pa- tients to level I data-we would have a lot of free time.}

the offices of the patients/surgeons/cardiologists who are making the recommendations/decisions right now! We don't have (and, will not soon, if ever, obtain) prospective randomized information comparing the various therapeutic strategies for atrial fibrillation. So, the current systematic review conscientiously analyzes the available, but admittedly noncomparable, studies. Some clinics performed the surgical thoracoscopic and catheter ablation simultaneously, and some performed these sequentially. They each use their own preferred radiofrequency/cryoablation for patients with both chronic and paroxysmal atrial fibrillation. The methods and duration of follow-up differ. The authors have tried to make practical clinical sense of the 22 heterogeneous clinical studies. Current consensus is that the zones surrounding the pulmonary veins are the most grievous culprits and left atrial exclusion/appendectomy is important.

As the "reduced morbidity" hybrid procedures evolve, the remaining questions relate to the variable importance of the additional "lesion set" lines. As of today, Varzaly and colleagues have contributed substantively to our decision-making process and our conversations with our patients.

\section{Reference}

1. Varzaly JA, Lau DH, Chapman D, Edwards J, Worthington M, Sanders P. Hybrid ablation for atrial fibrillation: a systematic review and meta-analysis. J Thorac Cardiovasc Surg Open. 2021;7:141-54. 